\title{
Core Inflation: The Malaysian Case ${ }^{\mathrm{i}}$
}

\author{
Mohd Helmi Ramlee ${ }^{1}$, Muhamad Shukri Abdul Rani ${ }^{2}$ \\ ${ }^{1}$ Department of Monetary Assessment and Strategy, Bank Negara Malaysia, Malaysia \\ ${ }^{2}$ Department of Financial Surveillance, Bank Negara Malaysia, Malaysia
}

Copyright@2016 by authors, all rights reserved. Authors agree that this article remains permanently open access under the terms of the Creative Commons Attribution License 4.0 International License

\begin{abstract}
Price stability is one of the primary goals of central banks. In assessing price stability, some central banks monitor core inflation rather than headline inflation, as it provides signal about persistent movements in inflation, which is important for the conduct of monetary policy. The objectives of this paper are threefold. First is to highlight the importance of core inflation to monetary policy. Second is to derive estimates of core inflation for Malaysia. Finally, it seeks to evaluate the performance of each measure of core inflation in forecasting headline inflation. We consider a number of measures for core inflation, and note their merits and demerits. Of significance is that each measurement performs differently when used to forecast headline inflation. This alludes to the possibility that some measures of core inflation could act as good predictors of future inflation, while others are best at describing current development.
\end{abstract}

Keywords Quantitative Methods, Price Indexes, Prices

JEL Classification Numbers: C1, E3

\section{Introduction}

Active research on core inflation has been on-going for quite some time and its importance in the study of inflation dynamics and discussions on monetary policy is well established. Wayne [1] (2008) reported that the term first appeared in an article written by Schreder [2] (1952) who used it in a discussion on the inflationary gap that the United States was undergoing in the early 1950s. During the period of high inflation and stagnant global growth of the 1970s, both Sprikle [3] (1975) and Tobin [4] (1981) use the term in their discussions on the short-term outlook of the American economy and of sacrifices ratios respectively. Blinder [5] (1997), meanwhile, provides a brief but important insight into how core inflation was measure and how it was used in policy discussions at the Federal Reserves ${ }^{1}$. Among other things, he said:

\footnotetext{
${ }^{1}$ He served as Vice Chairman from June 1994 - January 1996.
}

'...policymakers had to answer a key question: given the month-to-month inflation, how does one distinguish the signal from the noise. Or in other words, what part of the each monthly observation on inflation is durable and what part is fleeting?'

Today, that question remains valid and of even greater importance, in light of the recent spike in prices for global commodities that led to historically high levels of headline inflation in both advance and emerging economies. In the case of Malaysia, pertinent questions remain unanswered about core inflation, such as why should monetary policy focus on it and what measures could best represent it. To a certain extent, these questions were addressed by the Bank [6] in its Annual Report 2000 (Bank Negara Malaysia, 2000, p. 82-84).

Although the task is formidable, this working paper attempts to shed some light on the above key questions. Our research questions are as follow:

- Why should monetary policy focus on core inflation?

- Which measure of core inflation is best suited for accounting and forecasting headline inflation?

- What policy lessons could be learned?

There are, nonetheless, limitations to our work. First, we do not intend to promote any particular measure of core inflation. Rather, we would encourage the usage of multitudes of approaches to support policy analysis at the Bank. And second, we recognise that the ultimate aim of monetary policy is to ensure price stability and maximum attainable growth. Hence, there are bound to be conflict and concordance between the two axioms that we shall not cover.

Moving on, the lay out of this paper is as follow. In the next section, we survey the literature on the connection between total and core inflation, its concepts, properties and importance to monetary policy. In section 3 , we describe Malaysia's historical inflationary trends, followed by a short section on the consumer price index (CPI) data for Malaysia that will be used for measuring core inflation. The descriptions of the various measurements of core inflation and evaluations of their performance are presented later followed by a discussion. As our reader will later see, these 
measurements of core inflation perform differently when evaluated. This alludes to the possibility that some measures of core inflation could act as good predictors of future inflation, while others are best at describing and accounting current inflation. The final section concludes this paper.

\section{The Connection between Headline Inflation and Core Inflation}

Most central banks are concerned, and are task with achieving price stability. Price variability does carry some economic costs that both the Government and society would like to avoid. They could come in the form of eroded consumer purchasing power, lower tax revenues, or lower real benefits and wages for workers. Hence, this requires for continue surveillance of vital price statistics in order to be on guard against significant and volatile movements in prices.

Given such costs and concerns, monetary policy would need to focus on factors that drive the overall inflation away from its long-run trend. This would require a connection between overall inflation and core inflation to be established. Formally, Rogers [7] (1998) describe a short-run aggregate supply curve, based on Quah and Vahey [8] (1995) ${ }^{2}$ definition of core inflation, in the following manner:

$$
\pi_{t}=\pi_{t}^{L R}+g\left(x_{t-1}\right)+v_{t}
$$

where, $\pi_{t}$ is aggregate inflation at time $\mathrm{t}, \pi_{t}^{L R}$ is the long-run or trend inflation (which may be time varying), $g\left(x_{t-1}\right)$ stands for a measure cyclical excess demand pressure and $v_{t}$ is a measure of transient disturbances to inflation. Institutively, core inflation can be defined as $\pi_{c}=\pi_{t}^{L R}+g\left(x_{t-1}\right)$, which corresponds to the long-run component and any cyclical movements. It excludes temporary disturbances to inflation. This definition is consistent with the long-term view of a vertical Philips curve, where monetary policy affects only the general price level and not real macroeconomic variables. It brings to our attention that monetary policy should not react to short-term deviations in prices brought by temporary supply disturbances such as an oil price shock. However, one should recognize the potential threat of a 'second round effect' in motion as labours, under the influence of money illusion, demand higher nominal wages to compensate for their dwindling purchasing power. Under such circumstance, the risk of inflation expectations being un-anchored is real and warrants firm monetary policy actions. This undertaking, to a certain degree, requires one to have a good appreciation of the underlying inflation and a solid prognosis of future

\footnotetext{
${ }^{2}$ Quah and Vahey (1995) define core inflation as “.... as that component of measured inflation that has no medium to long-term impact on real output". In this context, inflation is output neutral given a vertical long-run Philips curve. This definition also excludes the permanent impact on price level stemming from supply shocks.
}

headline inflation.

Thus, the main motivation to focus on core inflation is because there is a significant amount of transitory noise in the monthly consumer price data. Removing these noises would allow the central bank to have a better sense of the underlying price movements (Rich and Steindel [9], 2007). Moreover, several studies have shown that over the long-term, overall inflation tend to revert more strongly to core inflation rather than the other way around (Mishkin [10], $2007)^{3}$. This suggests by focusing on core inflation, monetary policy could work to achieve its price stability objective. The following section takes us deeper into the discussion on core inflation.

\subsection{Core Inflation: Concepts and Properties}

\subsubsection{Concepts of Core Inflation}

Under the first concept, core inflation should be a good indicator of the underlying inflation trend, or technically as the persistent component of the measured inflation (Blinder [5], 1997; and Roger [7], 1998). This means it should be able to provide policymakers as much information about the underlying inflationary trend from the monthly CPI data. In general, the monthly CPI data could be quite confusing, especially when prices of some items in the CPI basket move in opposite directions. Moreover, prices of certain goods in the CPI basket are volatile by nature like fresh vegetables and fresh seafood, while some are much more stable, especially for goods whose prices are controlled by the Government. Hence, policymakers may need to decipherer the monthly CPI data in order to look for the persistent element of headline inflation that represents the process of continuously rising general prices and tends to incorporate future price directions and expectations. The success of identifying this element would be useful for policy deliberations, as it allows for near-term and long-term forecast of headline inflation. As Bernanke et al. [11] (1999) noted:

"The core CPI is likely to provide a better guide to monetary policy than other indices, since it measures the more persistent underlying inflation rather than transitory influences on the price level".

A second concept defines core inflation as the widespread or generalised aspect of inflation (Bryan and Cecchetti [12], 1993) that is able to describe what is happening to general prices in the current period, while ignoring temporary intermittent charges in prices. According to Clark [13] (2001), at any given point of time, prices of some items will rise above a certain trend-rate, while others will increase at a pace below it. Hence, core inflation should be able to isolate the common component in these price changes that

\footnotetext{
${ }^{3}$ Mishkin (2007) cited different studies on the US to support the reversion of headline inflation to core inflation over the long-run. However, results for other countries are more ambiguous.
} 
corresponds to the underlying trend in prices.

\subsubsection{Properties of Core Inflation}

Both Roger [7] (1998) and Silver [14] (2006) discuss at length on several desirable properties of core inflation as a useful indicator for monetary policy. First, it must be able to disentangle the persistent component of inflation from the transient movements, permitting for a better signal extraction process. This would prove useful in the conduct of monetary analysis and forecasting of future inflation.

Second, it must be credible. Having an independent body to compute and release measures of core inflation, instead of the central bank, would contribute towards enhancing public confidence and avoid controversies. Moreover, such public confidence would help to strengthen the central bank's credibility, especially if these measurements have some policy bearing.

The third quality is that it must be timely. Delayed information could compromise policy deliberations and hamper effective communication and monetary operations. In addition, such timeliness also promotes accountability on the part of the central bank, as it allows the monetary authority to explain deviations of headline inflation from its target to the public. Bernanke et al. [11] (1999) note:

“...use of a core CPI measure also helps the central bank to communicate to the public that not every shock that raises prices will lead to a permanent increase in the inflation, and that short-term changes in inflation resulting from supply shocks will be treated differently from changes driven by aggregate demand".

Finally, these measurements must be forward looking, especially when monetary policy works with a lag. Such delayed response will have significant repercussion on future levels of output and inflation. Without some bearing on the future, policy mistakes can be very costly and difficult to unwind.

\subsection{Why Should Monetary Policy Focus on Core Inflation?}

There are several answers to the above question. At the very top is the recognition that monetary policy works with a considerable and variable lag, and is unable to respond to short-term supply shocks or control temporary price deviations. As a result, headline inflation could be polluted by temporary price changes (noises) and may not reflect the underlying inflation that monetary policy aims to contain. More importantly, given the time lag, monetary authority would be much more interested in the outlook for inflation over some future horizon (Mankikar and Paisley [15], 2004). Removing these transient noises from the headline inflation allows one to have a better grasp of the underlying inflation and permits one to compare it to an explicit or implicit long-run target for price stability (Rich and Steindel [9], 2007).
Another important fact is that relative to the overall inflation, changes in core inflation are very unlikely to reverse within a short time frame. This suggests that over time headline inflation would revert to core inflation. One could see this from the preceding aggregate supply equation propose by Roger [7] (1998) where short-term deviations would cause headline inflation to move away from core inflation. Over time, once these shocks dissipate headline inflation would converge to core inflation. Various studies have been conducted to test whether the divergence between the headline inflation and core inflation is temporary or otherwise, with mixed results. For instance, Rich and Steindel [9] (2007) find significant reversion of headline CPI inflation to core CPI inflation over 12 quarters from 1978 to 2004. Their earlier work in 2005 using PCE4 price inflation for the 1978-2004 and 1959-2004 periods also yield similar results. Armour [16] (2006) studies the CPI inflation and core inflation for Canada and concludes core inflation measurements do provide unbiased forecast for future headline inflation and are useful indicators although forecast results are not entirely robust. Mankikar and Paisley [15] (2004) run some tests to check for convergence in the UK CPI inflation and core inflation series using a standard method proposed by Marques et al. [17] (2000). They find only three (out of 13) of the measures of core inflation pass all the necessary tests. Finally, a paper by OECD [18] (2005) finds headline inflation tends to revert to core inflation in the United States, Canada and Japan but not in the Euro Area and somewhat ambiguous for the UK.

Core inflation could also act as a useful short-term operational guide for the conduct of monetary policy to achieve price stability (Armour and Laflèche [19], 2006; Hogan et al. [21], 2001; Rich and Steindel [9], 2005). The resulting core inflation could be regarded as a measure of inflation that is the outcome of monetary policy. Hence, some measures of core inflation could be considered to be more controllable by the central bank. If the use of inflation targets implies the central bank is willing to assume responsibility for inflation ex post, it make sense to define the target as a measure of inflation for which it has the most ex ante control.

Focusing on core inflation may also help to limit potential policy mistakes (Armour and Laflèche [19], 2006; and Mishkin [10], 2007). Suppose in the past monetary policy was tightened following higher headline inflation due to some adjustments in fuel prices. With some degree of certainty, headline inflation would trend downwards once the effect of the price adjustments wear off after a year. However, the same cannot be said of the effects from a tighter monetary policy stance. Given the time lag, higher interest rates would affect both consumption and investment decisions by households and firms. This could result in a lower overall output and increase unemployment in the short

\footnotetext{
${ }^{4}$ Personal consumption expenditures (PCE) price index is compiled by the Bureau of Economic Analysis, USA.
} 
run, while raising inflation levels in the medium term. As the economy reacts to correct these imbalances, such swings could lead to more price and output volatility and run contrary to the central bank objectives of price stability and maximum attainable growth.

Finally, core inflation could be a good measure of inflation for policy formulation and Wayne [1] (2008) gives a good account of this. For example, some central banks, especially those that have adopted the inflation targeting ${ }^{5}$ framework, do adopt some measurements of core inflation in their policy deliberations and communication with the public. The Bank of Canada, for example, adopted inflation targeting in 1991. An agreement signed in 2006 between the Government of Canada and the Bank of Canada, reaffirms the inflation target at 2 percent, with a 'target range' of 1 to 3 percent. The central bank noted:

"...measures of core inflation, along with indicators of capacity pressures, have been shown to be useful indicators of underlying infatuation and, hence, or where total CPI inflation could be in the future. For this reason, core inflation provides a useful guide for the conduct of monetary policy".

Another example is the Reserve Bank of Australia, which regularly publishes a number of measures of core inflation in its quarterly Statement on Monetary Policy. In its Statement on the Conduct of Monetary Policy released in December 2007, the central bank highlighted that in its pursuit of medium-term price stability ${ }^{6}$, some recognition must be given for the natural short-run variation in inflation over the cycle. And finally, the Sveriges Riksbank (the Bank of Sweden), which adopted inflation targeting in 1993, routinely publishes measures of core inflation in its Monetary Policy Report. The CPIX, for instance, is defined as the CPI inflation excluding household mortgage interest expenditure, and direct effects of changes in indirect taxes and subsidies.

In the final analysis, core inflation has an important role in the deliberation and conduct of monetary policy. Besides being a forward indicator of headline inflation, core inflation could assist policy makers in communicating their monetary stance to the public. It could also provide the necessary check and balance to the macroeconomic analysis undertaken by the central bank, while safeguarding it from potential damages arising from costly policy mistakes.

\footnotetext{
${ }^{5}$ Inflation targeting is a framework for monetary policy characterised by the public announcement of official quantitative targets (or target ranges) for the inflation rate over one or more time horizons, and by explicit acknowledgement that low, stable inflation is monetary policy's primary long-run goal. Among other important features of inflation targeting are vigorous efforts to communicate with the public about the plans and objectives of the monetary authorities, and, in many cases, mechanisms that strengthen the central bank's accountability for attaining those objectives (Bernanke et. al. 1999, pg: 4).

Medium price stability is defined as keeping consumer price inflation between 2 and 3 percent, on average, over the cycle.
}

\section{Inflation in Malaysia}

For most of the time, inflation has remained quite low and relatively stable with an average of $2.9 \%$ over 56 years $(1956-2012)^{7}$. There are, however, bouts of high and low inflation periods, as highlighted in the following table. The first episode of high inflation took place in the 1972-74 periods following the first global oil price shock ${ }^{8}$. This reflects the impact from rapid world inflation, sharp increases in import prices, rapid growth of domestic aggregate demand and supply bottlenecks (Bank Negara Malaysia [6], 1979). Annual headline inflation rose to a record level of $17.3 \%$ in 1974 (1973: 10.5\%, 1972: 3.2\%). In the aftermath of the first oil price shock, the global economy grew at a modest pace of 2.8\% in 1974 (1973: 6.9\%, 1972: $5.5 \%$ ), while the impact on the Malaysian economy was felt a year later when it slowed to a mere 0.8\% (1974: 8.3\%, 1973: $11.7 \%$ ).

Table 1. Consumer Prices

\begin{tabular}{|c|c|c|c|c|c|c|}
\hline \multicolumn{7}{|c|}{ Average annual growth rate $(\%)$} \\
\hline Year & $\begin{array}{c}1956- \\
65\end{array}$ & $\begin{array}{c}1966 \\
-75\end{array}$ & $\begin{array}{c}1976- \\
85\end{array}$ & $\begin{array}{c}1986- \\
95\end{array}$ & $\begin{array}{c}1996- \\
05\end{array}$ & $\begin{array}{c}2006- \\
12\end{array}$ \\
\hline 1 & 0.8 & 1.0 & 2.6 & 0.7 & 3.5 & 3.6 \\
\hline 2 & 4.5 & 4.6 & 4.8 & 0.3 & 2.7 & 2.0 \\
\hline 3 & -1.4 & -0.1 & 4.9 & 2.6 & 5.3 & 5.4 \\
\hline 4 & -2.0 & -0.4 & 3.7 & 2.8 & 2.7 & 0.6 \\
\hline 5 & 0.0 & 1.9 & 6.7 & 2.6 & 1.5 & 1.7 \\
\hline 6 & -0.2 & 1.6 & 9.7 & 4.4 & 1.4 & 3.2 \\
\hline 7 & 0.1 & 3.2 & 5.8 & 4.8 & 1.8 & 1.6 \\
\hline 8 & 3.1 & 10.5 & 3.7 & 3.5 & 1.0 & \\
\hline 9 & -0.4 & 17.3 & 3.9 & 3.7 & 1.5 & \\
\hline 10 & -0.1 & 4.5 & 0.4 & 3.5 & 3.0 & \\
\hline Average & 0.4 & 4.4 & 4.6 & 2.9 & 2.4 & 2.6 \\
\hline
\end{tabular}

Source: Department of Statistics, Malaysia

${ }^{1}$ Data up to 1986 refers to Peninsular Malaysia only

In 1979, the world economy suffered its second energy crisis in the wake of the Iranian Revolution, and resulted in lower crude oil production in the affected producing countries $^{9}$. Prices for global crude oil rose sharply by an annual rate of $133 \%$ from USD12.78 per barrel to USD29.83 per barrel ${ }^{10}$. As a result of the supply shock, world inflation rose sharply from $9.9 \%$ in 1978 to $12.5 \%$ and $16.9 \%$ in 1979 and 1980 respectively ${ }^{11}$. In Malaysia, being a highly open economy, domestic prices were also affected by these

${ }^{7}$ Prior to February 1987, headline inflation in Malaysia is proxied by the CPI for Peninsular Malaysia (Ministry of Finance, 1985, p. 125).

${ }^{8}$ The first global oil shock saw price for WTI crude oil rose from an average of USD3.27 per barrel in 1973 to USD11.50 per barrel or at a shocking annual growth of $252 \%$.

9 Iran's daily crude oil production fell from 5.24 million barrels per day in to 3.17 and 1.66 million barrels per day in 1979 and 1980 respectively (Annual Energy Review 1995, Energy Information Administration, July 1996. p. $312)$.

10 Ibid.

11 Ibid 
external developments. In anticipation of the higher inflation in the latter part of 1979 and the following years, the Government reactivated the Standing Committee of Officials on Anti-Inflation in April 1979 to review the price situation and recommend measures to restrain inflation, with special emphasis given food production and agriculture productivity (Ministry of Finance, 1979. p 143). Moving on, headline inflation did rise steeper higher from $3.7 \%$ in 1979 to $6.7 \%$ and $9.7 \%$ in 1980 and 1981 respectively. The latter reflected the compounding effect of higher domestic prices due to the oil price shocks, supply shortages of essential items and the increase in domestic fuel prices ${ }^{12}$.

Notwithstanding the preceding two episodes of high inflation, Malaysia also experienced a period of very low inflation at the height of the economic recession in 1985-86 (Bank Negara Malaysia [6], 1994. p 23). Then, headline inflation rose marginally by $0.4 \%$ and $0.7 \%$ in 1985 and 1986 respectively (1984: 4.6\%). To some extent, this reflected lower prices for international commodities such as crude oil and non-oil products. Furthermore, the relatively stable prices in the OECD countries had resulted in lower import prices and coupled with Government led measures limited the pass-through to domestic prices (Ministry of Finance, 1985. p. 126).

Domestic headline inflation rebounded higher in the early 1990s following the build-up of inflationary pressures arising from five consecutive years of strong economic growth in excess of 8\% in 1988-92 (Bank Negara Malaysia [6], 1994, p. 23). Externally, the outbreak of the Gulf War following the invasion of Kuwait by Iraq in August 1990 pushed prices of global crude oil sharply higher by an annual rate of $28.4 \%$ in $1990^{13}$. Consequently, this led to a build up in inflationary pressures in both developed and developing countries. With some time lag, the impact from this external development, coupled with buoyant domestic demand, low unemployment and high capacity utilisation contributed to higher domestic inflation (Bank Negara Malaysia, 1999. p 18). Nevertheless, the impact of the higher global crude oil prices was not fully transmitted into domestic prices given the existence of Government's subsidy on the pump petrol prices (Ministry of Finance, 1990. p. 209). Other measures, both monetary and fiscal in nature, were also taken to moderate the increase in inflation (Ministry of Finance, 1991. p. 211).

Inflationary pressures began to build up towards the end of 1997, as the ringgit weakened to successive low in light of higher volatility following the onset of the Asian financial crisis. This resulted in higher import prices and contributed towards higher inflation, which increased by $5.3 \%$ in 1998 (1997: $2.7 \%$ ). The impact of the exchange rate depreciation, however, was not passed through to consumer prices as some producers, in an environment of weaker domestic demand,

\footnotetext{
${ }^{12}$ Domestic fuel prices were raised by an average of $9.1 \%$ and $9.9 \%$ in June and August 1979 respectively (Ministry of Finance, 1979. p 140)

Ibid
}

absorbed part of the higher cost of production to protect their market share (Bank Negara Malaysia [6], 1998, p. 72). Furthermore, the tighter monetary stance and fiscal prudence, coupled with lower global inflation and commodity prices, also had a dampening effect on the overall price level (Ministry of Finance, 1998, p.144).

In the build up of 2007-08 global commodity prices shock, headline inflation begin to creep up in the third quarter of 2007 following higher prices for global commodities such as crude oil and food products. Indeed, global prices for these major commodities have been increasing for quite a while and it was a matter of time before the effect was transmitted to local prices. Food prices, which increased steadily in 2007, were higher in 2008 following the global shortage of essential supplies of rice and wheat. Moreover, adjustments to retail fuel prices by the Government in June of 2008 have also contributed to higher inflation, which rose to $8.5 \%$ in the following month. In response, the Government introduced several short and long-term measures to deal with the domestic food crisis. These include increasing the purchase of rice from the global market and opening up more agriculture land. It also stepped up its surveillance and enforcement activities to weed out indiscriminate price increases by unscrupulous traders. Furthermore, a Special Cabinet Committee on Anti-Inflation was established in April 2008. It was tasked with looking into measures to ease the burden of the poor and vulnerable groups in coping with rising costs of food and energy. It was later replaced by the Economic Council in August of the same year, which acts as an advisory body to recommend measures to sustain economic growth, in light of the global economic slowdown and to identify approaches to contain inflationary pressures (Ministry of Finance, 2008, p. 86).

Subsequently, inflation also increased but at a more moderate pace in 2011 at $3.2 \%$ (2010:1.7\%) due to surged in global commodity prices. Global crude oil and food prices increase by $35 \%$ and $26 \%$ respectively between January 2010 and September 2011 with a notable increase of $94 \%$ in the global price of corn due to disruption in supply and low stockpiles. There is also adjustment in price administered items in line with the introduction of subsidy rationalisation program by the Performance Management \& Delivery Unit (PEMANDU) under the Prime Minister's Department. Nevertheless, as the price adjustment was gradual and paced, the knock-on effects on other goods and services are relatively contained as businesses were better able to cope with the rise in costs.

\section{Measurements of Core Inflation}

\subsection{Statistical-based Measurements}

The measurements of core inflation are divided in to two classes. In the following sub-section, we will survey the statistical-based approach to computing core inflation. To 
accomplish this, we would need to rely on the 4-digit consumer price index (CPI) data, which were sourced from the Department of Statistics Malaysia. In all the CPI data at the 3-digit level are classified into 12 main categories and can be further divided into 51 sub-categories (see appendix 1). The data start from January 1992 until December 2012 and are re-based to the latest base year $(2010=100)$. Meanwhile, the annual growth of the CPI inflation is computed from January 1993. We begin the statistical-based approach with the exclusion-based method and end it with the exponential smoothing technique. Corresponding charts comparing each measure of core inflation with headline inflation are display in the appendix.

\subsubsection{Exclusion-based Method}

The exclusion-based method of calculating core inflation is by far the most widely used technique to date and often receives the most public attention. In this case, some components of the CPI such as selected food items, price volatile items or prices of goods controlled by the Government are permanently excluded from the calculation of core inflation ${ }^{14}$. The economic rationale for excluding certain items from the calculation of core inflation is because they are most likely to be affected by supply-side disruptions, which are expected to be temporary and would wane after a certain time period. As discussed, monetary policy should instead focus on factors that affect aggregate domestic demand and not on temporary disturbances.

This method is often cited for its advantages, namely timeliness, clarity and easy to understand by the public. However, critics often argue it lacks clear economic reasoning and the subjective exclusion of certain items, especially food and energy prices could be a drawback given that they could be carrying important signals to policymakers. For example, Bean [20] (2006) noted that the exclusion of high energy prices, while retaining falling goods prices, from the calculation of core inflation may render it misleading. Mankikar and Paisley [15] (2004) argue the exclusion of energy prices such as the price of retail fuels could leave out valuable information about the underlying inflation since the former could also be driven by persistent global demand conditions.

For our purpose, we have selected certain items that would be excluded from the core CPI computation. These items were excluded due to their volatile nature (such as fresh seafood and vegetables) or are susceptible to supply shocks or are controlled either directly or indirectly by the Government (rice, petrol and diesel). Specifically, price-volatile goods include items that have high degree of price volatility (high variance) that are predominantly influenced by supply shocks. For our purpose, item that are assumed to be subjected to supply shocks is excluded from

\footnotetext{
${ }^{14}$ In the UK, mortgage interest payments and effects of indirect taxes are excluded (Mankikar and Paisley [15], 2004), while in Canada eight sub-indexes plus effects of indirect taxes are removed from the calculation of core inflation (Hogan et al [21], 1999).
}

the computation of core inflation. Meanwhile, the price-controlled goods refer to controlled items that are under the Price Control Act, 1946 and Control of Supplies Act, 1961, also excluded from the construction of core inflation. Finally, prices of goods that require the Government's approvals with the following characteristics are also excluded:

- Public goods such as public transport and utilities

- Items of which changes in Government tax would have a direct impact on its prices (cigarette and alcoholic beverages)

Thus, in all, 27 items from the CPI basket are excluded, accounts for $33.5 \%$ of the total CPI weight.

\subsubsection{Trimmed Mean}

Trimmed-mean is a limited influence estimator 15 proposed by Bryan and Cecchetti [12] (1993), which refers to the weighted-average inflation rate of the components of the CPI basket, excluding inflation rates at the extreme of the range - the lowest and highest end. The basis for trimming is that changes in prices at the extremes of the distribution may contain less information about current underlying inflation than those lying towards or at the centre of the distribution. Another way to look at it is based on a proposition that items that have extremely low inflation rate are presumably subject to administered or control items, while items that have extremely high inflation rates are presumably subject to supply shock. By excluding these items, the re-computed inflation rate would be more reflective of monetary inflation, which is influenced largely by changes in demand conditions. For our purpose, for each month, the CPI items are re-arranged, with the lowest inflation being the first and the highest inflation being the last. The cumulative weight is then computed. For the computation of trimmed-mean, items in the first and the last $15 \%$ of the distribution are excluded from the original CPI basket, so that we maintain only $70 \%$ of total weights ${ }^{16}$.

\subsubsection{Weighted-Median (WM)}

The weighted-median inflation is another family member of the limited influence estimator, where the median is the 50th percentile inflation rate at which half of the components in the CPI basket have higher inflation and the other half, less. One clear advantage of this and the previous method is that both are rule-based and this eliminates any arbitrary exclusion of the CPI items (MAS [22], 1998). Moreover, these two techniques remove the impact of extreme or outlier price changes (both positive and negative) from the overall inflation.

\footnotetext{
${ }^{15}$ Limited influence estimators emphasise greater weight on the price trend or tendency of prices, and less or no weight on extreme or 'outlier' price movements (MAS [22], 1998).

${ }^{16}$ In New Zealand and Australia, the trimming rate is $5 \%$ \& $15 \%$ on each side of the price distribution (RBNZ \& RBA technical notes).
} 


\subsubsection{Double Weighted}

This method hinges on the notion that one should assign a lower weight to highly volatile CPI items and more weight to items that are not (OECD [18], 2005; Khong [23], 2006). Effectively, instead of removing volatile items, this method minimises or mutes their effects on headline inflation. Its advantage over other statistical methods is that all of the CPI items are included in the derivation of core inflation. This would address concerns over the possibility that some excluded CPI items may contain signals that are important to monetary policy.

\subsubsection{Exponential Smoothing}

Finally, Cogley [24] (2002) proposes an exponentially smooth measure of core inflation designed to track sudden and persistent movements in inflation, such as those arising from changes in monetary policy. In brief, this technique involves the exponential smoothing of current and past aggregate price changes.

Formally:

$$
\approx=g_{o} \sum_{j=0}^{\infty}\left(1-g_{o}\right)^{j} \pi_{t-j}
$$

where core inflation is define as a one-sided geometric distributed lag ${ }^{17}$ of current and past inflation $\left(\pi_{t}\right)$. According to the author, this particular technique can be apply in real time and has only one free parameter $\left(g_{0}\right)$, which could be calibrated up front. As a consequent, the filter coefficients will remain unchanged as new data are available and the historical core inflation series need not be revised. In the original paper, the author suggests a parameter setting of 0.125 for $\left(g_{0}\right)$.

\subsection{Model-based Approach}

In recent years, many researchers have developed core inflation measures based on econometrics modeling due to its unobservable nature. This improves the robustness of these measures since they are usually constructed based on sound economic theory. We could use multivariate analysis by using non-price variables to derive core inflation. But one must always remember the pertinent constraints related to this approach. Even though a model is grounded in economic theory, it is not within the grasp of the general public. One can also argue the assumptions and restrictions imposed are rarely uncontroversial. This makes these models sensitive to their exact specifications and identification schemes. Early work on modelling core inflation has been carried out by Quah and Vahey [8] (1995), Coimbra and Neves [25] (1997) and Velde [26] (2006).

\footnotetext{
${ }^{17}$ An example of a geometric distributed lag is the Koyck lag.
}

\subsubsection{Quah and Vahey - SVAR Model ${ }^{18}$}

Quah and Vahey SVAR model is known as the output-neutral core inflation model. It is based on the proposition that inflation is a result from perturbations ${ }^{19}$ to the economy over time. These perturbations can be separated into those that do not affect real output in the long run such as nominal demand shocks and those that do. Core inflation is defined as the function of long-run trend inflation rate plus the cyclical excess demand pressure that has long-run impact on real output. Inflation as defined by these authors:

$$
\pi_{t}=\pi^{L R}+g\left(X_{t-1}\right)+v_{t}
$$

where core inflation is defined as:

$$
\pi_{t}^{c}=\left[\pi_{t}-v_{t}\right]=\pi_{t}^{L R}+g\left(X_{t-1}\right)
$$

In their model, Quah and Vahey tried to capture the inflation pressure that feed into inflation expectation (Mankikar and Paisley [15], 2002). This is reflected via core

\footnotetext{
${ }^{18}$ An alternative interpretation of core inflation is given by Eckstein [27] (1981). He defines core inflation as the trend increase of the cost of factors of production originating from the long-term expectations in households and businesses. Inflation, according to him, is define as $p=p_{c}+p_{d}+p_{s}$, where $p_{c}$ is the core component that is related to the steady-state factor price growth, $p_{s}$ is the shock component that captures the effects of exogenous changes and $p_{d}$ is the demand component, which reflects the effects of deviation of unemployment from its neutral rate. Hence, core inflation is defined as:

$\pi_{t}^{c}=\pi_{t}^{L R}=\pi_{t}-g\left(X_{t-1}\right)-v_{t}$

Where

$\pi_{t}^{c}$ is the aggregate inflation in period $\mathrm{t}, \pi_{t}^{L R}$ is the long-run or trend inflation rate, $g\left(X_{t-1}\right)$ represents a measure of cyclical excess demand
} pressure and $U_{t}$ is a measure of temporary disturbances to inflation. The core inflation components are a function of trend inflation or the aggregate inflation minus the cyclical excess demand pressure and the temporary disturbances to inflation.

One should note the difference in core inflation definitions between Eckstein's model and Quah and Vahey's model. The main difference between the two models is the former stresses that core inflation should not be cyclical where else the latter argues that core inflation should be cyclical and correlated with output in the short-run. This subtle difference is important. If the policy horizon is in the short to medium term, then policy makers can make use of the Quah and Vahey model. On the other hand, if the policy horizon is in the long-run, then the Eckstein's model is more suited. Laidler [28] (1990) consider Eckstein as the person who coined up the term core inflation.

Given data unavailability, we are unable to construct a core inflation series based on this model. The model is presented for completeness.

One should note the difference in the definition of core inflation between Eckstein and Quah and Vahey. The main difference between these two models is Eckstein's model stresses that core inflation should not be cyclical where else Quah and Vahey argue that core inflation should be cyclical and correlated with output in the short run. This subtle difference is important. If the policy horizon is in the short to medium term, then policy makers can make use of Quah and Vahey model. On the other hand, if the policy horizon is in the long run then the Eckstein's model is more suited.

${ }_{19}$ Perturbation refers to an alteration of the function of an economic system, induced by external or internal mechanisms (Monetary Authority of Singapore [22], 1998). 
inflation which is the component of inflation that is attributed to nominal demand shocks and thus, is consistent with the long-term view of a vertical Phillips curve. These mean monetary policy shocks have no lasting impact on real output but will ultimately affect inflation. Hence, monetary policy should avoid from responding to price changes arising from supply-side shocks (Monetary Authority of Singapore [22], 1998).

\subsubsection{Principal Component Analysis}

Principal component analysis is a vector space transformation which is often used to reduce multidimensional data sets to lower dimension for analysis purposes. These techniques have been used quite commonly in multivariate analysis. Coimbra and Neves first introduced the concept of using principal component analysis to measure core inflation in 1997. This approach was further explored by Machado et al [29] (2001) and Maria [30] (2004).

By using this method, core inflation is derived from information contained in the main components of the CPI. The main idea behind this method is to have a technique that could estimate price developments in the CPI main components and categorise them as the trend inflation indicator. The problem with this method, however, is the non-stationary behaviour of CPI main components. There are a few remedial measures that have been proposed to counter this problem such as running an OLS regression between inflation rate and the principal component, stacking lagged variables to the original datasets (Stock and Watson [31], 1998) and including more principal components in the derivation of core inflation.

\subsubsection{Kalman Filter}

In brief, the Kalman filter is a recursive filter that estimates the state of a dynamic system from a series of noisy measurement. This means only the estimated state from the previous time step and the current measurement are needed to compute the estimate for the current state. In contrast to batch estimation techniques, no history of observation or estimates is required.

Velde [26] (2006) introduce the concept of Kalman filter as an alternative measure of core inflation. He applies the Kalman filter state space modelling, consisting of the latent inflation $^{20}$, as an unobservable variable to simultaneously affect a collection of individual price series. From his results, the latent inflation and the core inflation ${ }^{21}$ series have similar movement. He finds out that the latent inflation reduces the out-of-sample forecasting error ${ }^{22}$, thus making it useful for forecasting purposes.

\footnotetext{
${ }^{20}$ Latent inflation here refers to core inflation measure by using Kalman filter.

${ }^{21}$ Core inflation here refers to core PCE by U.S. Bureau of Economic Analysis.

${ }^{22}$ This is because the Kalman filter eliminates the noise in individual price series.
}

\subsection{Hybrid Model}

The hybrid model is a new line of study to measure core inflation. We call it a hybrid model because we can't classify this new breed of core inflation measure to either statistical approach or model based approach due to its unique nature. There are two measures under the hybrid model namely the Domestically Generated Inflation (DGI) and Wavelet Analysis.

\subsubsection{Domestically Generated Inflation Model}

Domestically Generated Inflation (DGI) is a measure of core inflation that would prevail absent of external shocks to the economy, such as a large movement in the exchange rate. This method was first introduced by Buiter [32] in 1998. For the purpose of this paper, we derived the equation of DGI as;

$$
\begin{aligned}
& \pi_{t}=\pi_{t-1}+\beta_{1}\left(y_{t-i}-y_{t-i}^{p}\right)+\beta_{2}\left(\Delta y_{t-i}-\Delta y_{t-i}^{p}\right)- \\
& -\beta_{3}\left(\dot{e}_{t-i}+\pi_{t-i}^{w}\right)+\beta_{4}\left(s_{t-i}+\pi_{t-i}^{k}\right)+\beta_{5}\left(w g_{t-i}+p d_{t-i}\right)+\varepsilon_{t}
\end{aligned}
$$

where;

$$
\begin{gathered}
=\text { Headline Inflation, } \\
\left(\mathrm{y}_{\mathrm{t}-\mathrm{i}}-\mathrm{y}_{\mathrm{t}-\mathrm{i}}\right)=\text { Output Gap, } \\
\mathrm{e}=\text { NEER (Nominal Effective Exchange Rates), } \\
\mathrm{s}=\text { Spot Exchange Rates (RM/USD), } \\
\mathrm{w}=\text { World Inflation, } \\
\mathrm{k}=\text { World Commodity Price, } \\
\mathrm{wg}=\text { Wages, } \\
\mathrm{pd}=\text { Productivity, } \\
\varepsilon_{\mathrm{t}}=\text { Residual term. }
\end{gathered}
$$

We exclude the impact of exchange rate and world inflation to core inflation and project the underlying domestic generated inflation.

DGI is useful in providing information on the pressures being exerted on prices by domestic conditions. If DGI has strong inertia, it would be a leading indicator to the actual headline inflation during an external shock. However, this measure is sensitive to the precise assumptions underlying its construction.

\subsubsection{Wavelet Analysis}

The wavelet analysis can be defined as a "waveform of effectively limited duration that has an average value of zero" (Misiti et al [33], 2000). This method was tailor-made for de-noising (or signal extraction from) non-stationary time series and is commonly used in applied science and engineering field such as earthquake predictions. The wavelet analysis was first brought to the economic mainstream by Schleicher [34] (2002) from the Bank of Canada. In his paper, he uses the wavelet for frequency 
domain analysis, non-stationary and complex function, long-term processes, time-scale decomposition and forecasting. He also discusses the time-scale decomposition by Ramsey and Lampart [35] (1998), which uses the wavelet analysis to study the relationship between money and income.

Cotter and Dowd [36] (2006) use the wavelet analysis to estimate core inflation. They obtain the core inflation rate by extracting the signal from the inflation series. By doing this, they actually applied an approximation to remove noises and reveal the underlying signal of inflation. To make sure the amount of noise removed is optimal (not too much or too little), we can checked for normality of details ${ }^{23}$ and minimum entropy ${ }^{24}$.

In choosing the type of wavelet to use, it is desirable to restraint ourselves with a wavelet that will generate the most optimal outcome (i.e. smooth core inflation series). Once one has decided on the type of wavelet to be used, the Jarque-Bera estimation could be tested on each wavelet. Wavelets with unreasonable Jarque-Bera probabilities values are eliminated. Estimates of the entropies for the remaining wavelets are carried out and wavelets with the least permissible criteria are removed. In case one needs to further eliminate more wavelets, he or she could look at the trend of each wavelet and eliminate those that look similar to each other (Cotter and Dowd [36], 2006).

\section{Evaluating the Measures of Core Inflation}

The different nature and methodology of each preceding measures of core inflation begets the question: how best do they explain and forecast headline inflation. Our prognosis at this juncture is that some measures of core inflation will do best at forecasting headline inflation, while the rest may be more suited at explaining current developments. This thesis needs to be corroborated and in this section, we propose a standardised methodology to check which measure of core inflation provides the most information about future headline inflation and which could help us to better understand current developments. The first test considers the volatility of each core inflation measures. This is follow by tests for the absence of bias and finally, we test the predictive power of each measure to forecast future headline inflation at different time horizons.

\subsection{Volatility of Core Inflation Measures}

The purpose of measuring the volatility is premise on the foundation that in order for core inflation measures to properly capture trend inflation, they should be less volatile

\footnotetext{
23 Normality of details here means that, the process of removing the noise should stop before it becomes normally distributed.

Entropy is signal at various frequency levels. Minimum entropy here means that we would opt for the lowest entropy.
}

that headline inflation (Armour [16], 2006). Here the relevant means and standard deviations are presented in the following table. For the sample period, January 1993 to July 2013, the trimmed mean have the smallest standard deviation, with exponential smoothing and Kalman filter recording smallest coefficient of variation. For robustness, we also present the mean absolute deviation (MAD) for each measurement, which shows the trimmed mean and weighted median having the smallest MAD compared to other measurements. To further augment this finding, we proceed to check for the presence of biasness in the core inflation series.

Table 2. Summary statistics for core inflation measures

\begin{tabular}{|c|c|c|c|c|}
\hline \multicolumn{5}{|c|}{ Sample period: Jan 1993 - July 2013} \\
\hline & Mean & $\begin{array}{l}\text { Standard } \\
\text { deviation }\end{array}$ & $\begin{array}{l}\text { Coefficient } \\
\text { of variation }\end{array}$ & $\begin{array}{c}\text { Mean } \\
\text { Absolute } \\
\text { Change }\end{array}$ \\
\hline Headline inflation & 2.7 & 1.6 & 0.6 & 1.2 \\
\hline $\begin{array}{l}\text { Exclusion-based } \\
\text { Method }\end{array}$ & 2.7 & 1.6 & 0.6 & 1.4 \\
\hline Trimmed Mean & 1.7 & 0.9 & 0.5 & 0.7 \\
\hline Double Weighted & 1.9 & 1.1 & 0.6 & 0.8 \\
\hline Weighted Median & 1.7 & 1.0 & 0.6 & 0.7 \\
\hline $\begin{array}{c}\text { Exponential } \\
\text { Smoothing } \\
\end{array}$ & 2.7 & 1.0 & 0.4 & 0.9 \\
\hline Kalman Filter & 2.7 & 1.0 & 0.4 & 0.9 \\
\hline $\begin{array}{l}\text { Principal } \\
\text { Component } \\
\text { Analysis }\end{array}$ & 2.7 & 1.6 & 0.6 & 1.2 \\
\hline SVAR & 2.6 & 2.0 & 0.8 & 1.4 \\
\hline Wavelet Analysis & 2.6 & 1.2 & 0.5 & 1.0 \\
\hline DGI & 1.2 & 1.2 & 1.0 & 0.9 \\
\hline
\end{tabular}

\subsection{Unbiasedness}

In the spirit of Bryan and Cecchetti [12] (1993), Heath et al. [37] (2004) and Silver [14] (2006), headline inflation could be decomposed in to the following form:

$$
\pi_{t}=\pi_{t}^{c}+v_{t}
$$

where in any period $t, \pi_{t}^{c}$ is a measure of core inflation and $v_{t}$ is a temporary disturbance term. This equation highlights the potential for headline inflation to deviate from core inflation over a certain period due to some short run supply shocks. In the absence of such shocks, there should not be any significant difference between both headline inflation and core inflation, implying unbiasedness of the later.

We test for unbiasedness of each core inflation measure by estimating the following equation $\pi_{t}=\alpha_{0}+\beta \pi_{t}^{c}+v_{t}$ and testing the joint null hypothesis that $\alpha=0$ and $\beta=1$, via the Wald Coefficient Restriction test. 
Table 3. Test for Unbiasness

\begin{tabular}{|c|c|c|c|}
\hline & $\alpha$ & $\beta$ & p value \\
\hline Exclusion-based Method & 1.02 & 0.64 & $0.0000^{*}$ \\
\hline Trimmed Mean & 0.39 & 1.43 & $0.0000^{*}$ \\
\hline Double Weighted & 0.53 & 1.22 & $0.0000^{*}$ \\
\hline Weighted Median & 1.06 & 1.03 & $0.0000^{*}$ \\
\hline Exponential Smoothing & 0.75 & 0.89 & 0.7038 \\
\hline Kalman Filter & -0.47 & 1.14 & $0.0018^{*}$ \\
\hline Principal Component Analysis & 0.48 & 0.82 & $0.0004^{*}$ \\
\hline SVAR & 1.32 & 1.05 & $0.0000^{*}$ \\
\hline Wavelet Analysis & -0.38 & 1.12 & $0.0413^{*}$ \\
\hline DGI & 0.77 & 0.67 & $0.0000^{*}$ \\
\hline
\end{tabular}

*significant at $10 \%$ level

The p-values indicate that we have to reject the null hypothesis and conclude that all of the core measures, with the exception of the exponential smoothing, are bias with respect to headline inflation. One plausible reason for these bias results, as suggested by Armour [16] (2006), is the presence of high skewness and kurtosis relative to a normal distribution in the CPI data. Hence, it is possible that the CPI data are inherently bias upward from the start.

\subsection{Predictive ability}

Finally, we test the predictive power of each core inflation measurement with the aim at finding which of these measures forecast headline inflation best. It is worth noting that many researches have undertaken this task, with mixed results $^{25}$. The univariate approach, based on Bryan and Cecchetti [12] (1993), requires one to regress headline inflation on different core inflation estimates at various time horizons and calculating the root mean square error (RMSE) for the in-sample forecast of the model ${ }^{26}$. This simple model can be described by the following notation:

$$
\pi_{t}^{k}=\alpha+\beta\left(\pi_{t}^{c}-\pi_{t-12}^{c}\right)+\varepsilon_{t}^{k, m}
$$

where the left hand side is the average inflation over $\mathrm{K}$ horizon, set at 12 and 24. Our interest is in the RMSE deviation between average inflation and core inflation. The above equation was regressed from the start of the sample period to December 2006 and the results were used to build an in-sample forecast for the January 2007-November 2008 sub-period.

In general, all measures of core inflation have smaller RMSE in the 12-months forecast horizon compared to the two-year window. However, the double weighted measure and wavelet analysis have the smallest RMSE for the shorter

\footnotetext{
25 Bryan and Cecchetti [12](1993), Blinder [5] (1997) and Cogley [24](2002).

Bryan and Cecchetti [12] (1993) conduct an out-of sample forecast for a few candidates of core inflation such as weighted median, $15 \%$ trimmed mean and CPI excluding food and energy components, as well as, headline inflation.
}

forecast horizons, while the trimmed mean performs better over the 24-months window. The latter's nature of minimising the impact of extreme price inflation in the computation of core inflation could lend support for a better predictor of headline inflation over a longer policy horizon.

Table 4. Predictive Ability*

\begin{tabular}{|c|c|c|}
\hline Predictive ability & \multicolumn{2}{|c|}{ RMSE } \\
\hline Measures & 12-months & 24 -months \\
\hline Exclusion-based Method & 0.84 & 2.02 \\
\hline Trimmed Mean & 0.62 & 1.39 \\
\hline Double Weighted & 0.60 & 1.52 \\
\hline Weighted Median & 0.97 & 2.11 \\
\hline Exponential Smoothing & 0.67 & 2.11 \\
\hline Kalman Filter & 0.80 & 1.63 \\
\hline Principal Component & 1.01 & 2.29 \\
\hline Analysis & 0.58 & 1.50 \\
\hline Wavelet Analysis & 0.69 & 2.14 \\
\hline DGI & 0.68 & 1.57 \\
\hline SVAR & & \\
\hline
\end{tabular}

*In sample forecasting

As a check to the above method, we perform a second test for predictive power based on Laflèche [19] (1997). In notational form:

$$
\pi_{t}=\alpha+\beta_{1} \pi_{t-12}+\beta_{2} \pi_{t-12}^{*}+v_{t}
$$

where, $\pi_{t}$ is the year-on-year percentage change of total CPI and $\pi_{t}^{*}$ is a candidate measure of core inflation. In similar fashion to the previous method, we performed a regression based on the above equation from January 1993 to December 2006 and performed an in-sample forecast for the January 2007-November 2008 sub-sample period. We follow Lefleche [19] (1997) by judging our assessment of the predictive power of each core inflation measure based on the adjusted coefficient of determination $\left(\bar{R}^{2}\right)$, where one could see the Kalman filter and wavelet analysis methods have the highest adjusted coefficient of determination followed by the Double Weighted Measure.

Table 5. Predictive Ability

\begin{tabular}{|c|l|}
\hline Predictive ability & $\bar{R}^{2}$ \\
\hline Exclusion-based Method & 0.12 \\
\hline Trimmed Mean & 0.02 \\
\hline Double Weighted & 0.17 \\
\hline Weighted Median & 0.01 \\
\hline Exponential Smoothing & 0.01 \\
\hline Kalman Filter & 0.47 \\
\hline CPI & 0.01 \\
\hline Principal Component Analysis & 0.11 \\
\hline Wavelet Analysis & 0.31 \\
\hline DGI & 0.07 \\
\hline SVAR & 0.01 \\
\hline
\end{tabular}


The results from the previous three sub-sections seem to point us towards a single but important conclusion that no single technique is superior to the other. While some measurements may exhibit lower volatility, it does not guarantee they make good candidates for forecasting future headline inflation. Furthermore, the present of biasness in the CPI data requires one to be extra careful when interpreting these results. Nevertheless, this brief deduction does not negate either of the techniques. What is more important for all users is to utilise all available measurements of core inflation to support their analysis of price developments and buttress their deliberations and conclusions with a thorough understanding of the economy and comprehensive macroeconomic surveillance. Frictions within the economy could easily lead to price pressures and could signal higher headline inflation in future. Monetary policy must be on guard against signs of second round effects which could lead to increasing demand for higher wages and un-anchoring of inflation expectations.

\section{How Data from Core Inflation are Analysed?}

The contribution of these core inflation series to policy deliberations can be seen from the following two contrasting episodes of high inflation, e.g. February 2006 - March 2007 and January - November 2008. In the first instance, various measures of core inflation seem to indicate that the underlying inflation was lower than headline inflation during this period. Headline inflation rose sharply to $4.8 \%$ in March
2006, in contrast to the simple average for all core inflation measures which stood at $2.2 \%$. In retrospect, the higher headline inflation was largely due to the increase in prices of fuels and lubricants in the transport category of the CPI following the sharp upward momentum in the international oil prices in early 2006. The absence of a second round effect at that time supported the belief most firms were able to absorb the extra production cost so as not to lose their market share.

Nevertheless, between January-November 2008, the general movement in all core inflation series, as shown in the following chart, seems to corroborate the trajectory of headline inflation. As prices for major global commodities, such as crude oil and food cereals, rose sharply, headline inflation began to creep upward fuelled by higher domestic food prices. This reflected the pass-through from higher external food prices to domestic food prices, as firms passed on the higher cost of production to domestic consumers. Given such an inflation outcome, a key policy consideration for the central bank was to ensure that such price adjustments did not translate in to a demand-driven inflationary pressure. This was supported by indicators of inflation expectations that gave the impression that inflation expectations have remained anchored. Notwithstanding this, realising the root cause of higher inflation was supply-related the Government announced several immediate and long-term measures to address inflationary pressures and potential supply bottlenecks. These measures are beginning to bear some fruits as both headline and some measures of core inflation have begun to decline in the recent period.

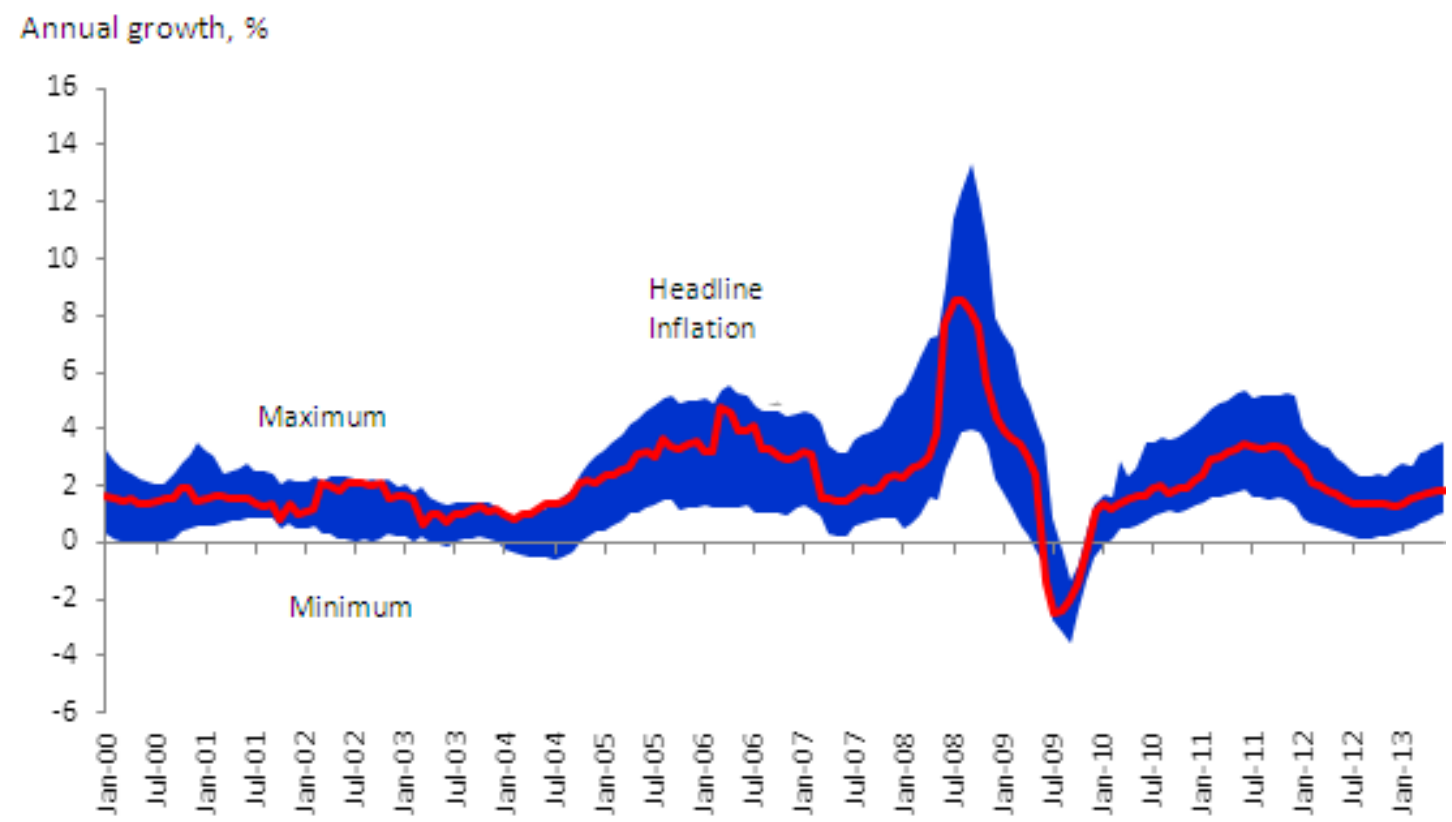

Figure 1. Core Inflation - Interval of Uncertainty 


\section{Conclusions}

Recognising the fact that future movements in headline inflation could be influenced by current core inflation, it is important to ensure measures of the former are available and robust to aid any policy deliberation. In this research paper, we have highlighted the concept of core inflation, its qualities and evaluated several candidate measures. We have find that each measure of core inflation perform differently when tested. How can one rationalise this conclusion? In some way, this conclusion alludes to the possibility that some measures of core inflation could act as good predictors of future inflation, while others are best at describing current development in headline inflation. Another way to look at it is that not a single measure of core inflation is superior to the other and thus, it would be wise for policy makers to consider all available information before coming to a conclusion. Therefore, we would like to reiterate our stance that it is important for one to be careful when making deductions about the underlying inflation. Moreover, policymakers should recognise the need to support their analysis with an array of supporting evidence in order to maximise the usefulness of these underlying measures of inflation in corroborating their policy analysis.

\section{Appendix}

\section{Group and Subgroups in Malaysia CPI (2010=100)}

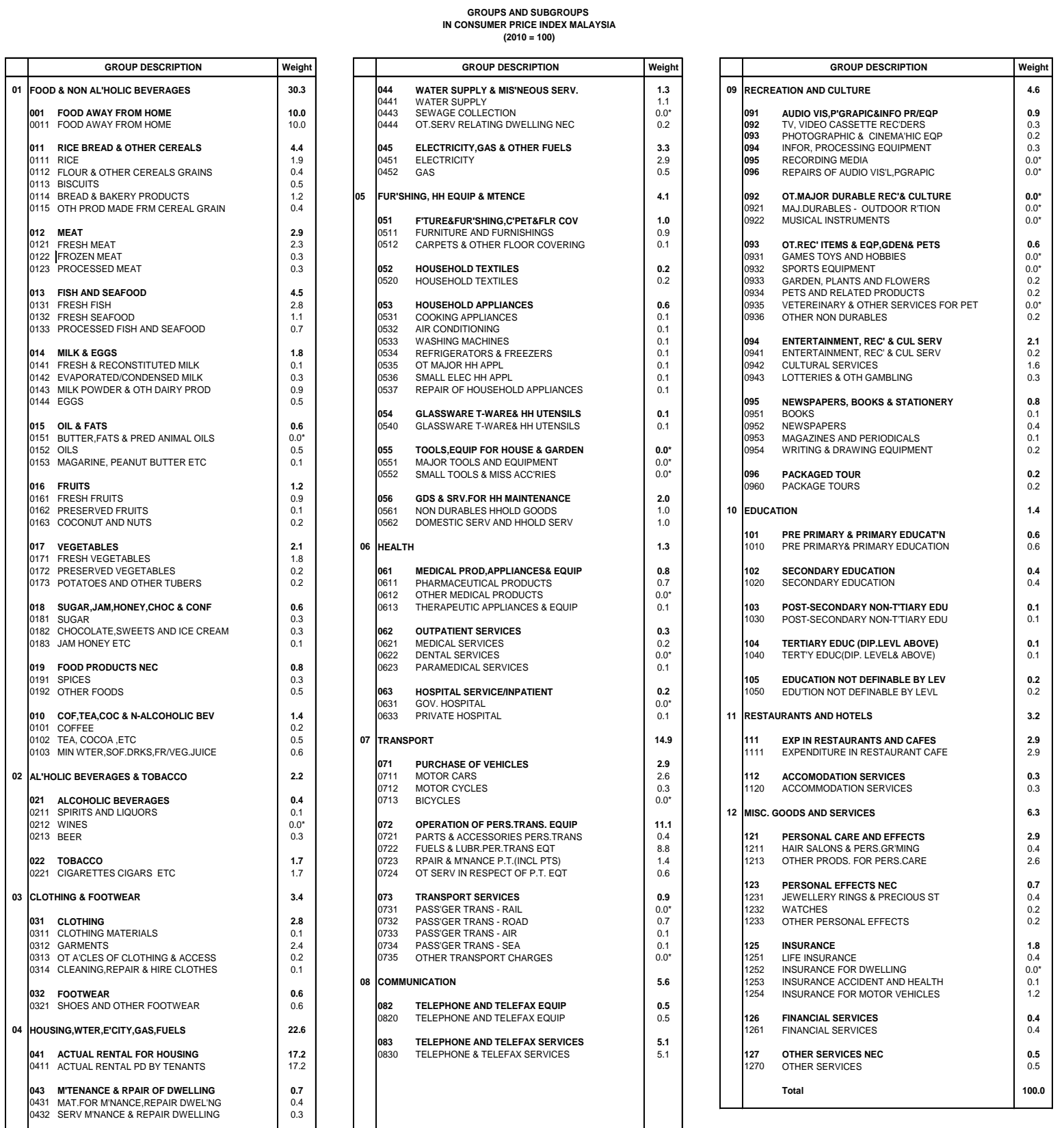


II. Plot of Headline Inflation against Statistical based Core Inflation Measures.

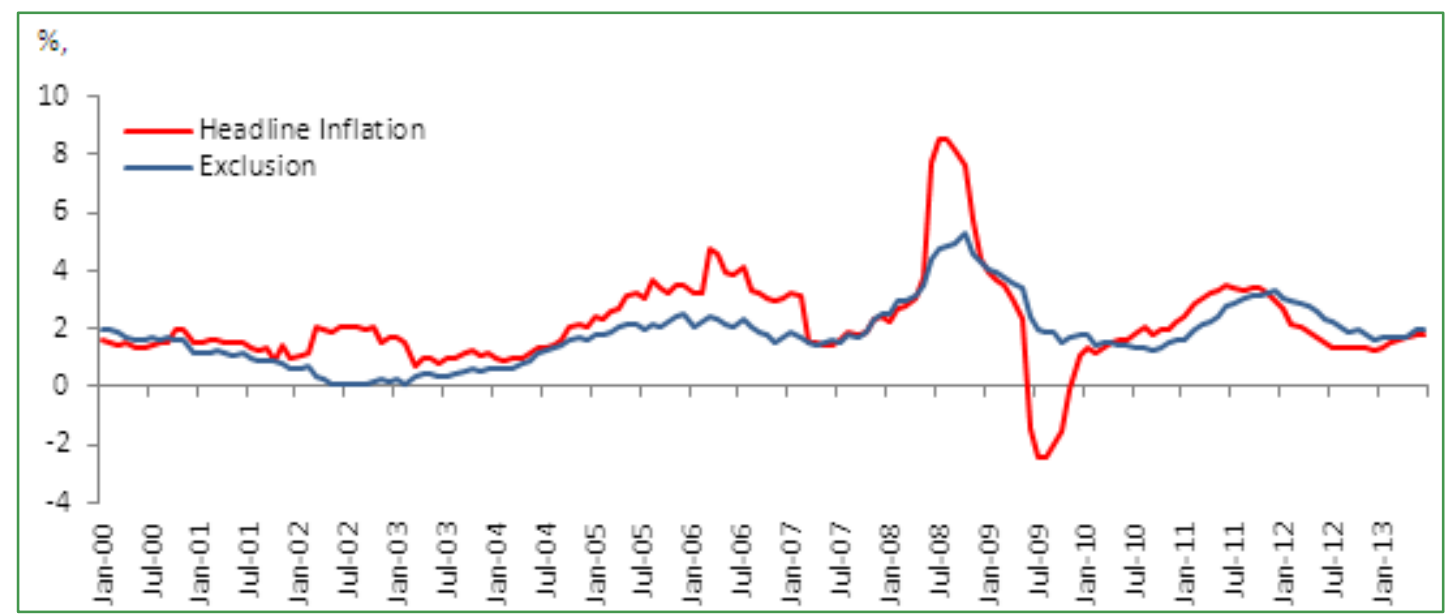

Figure 2. Headline Inflation and Exclusion

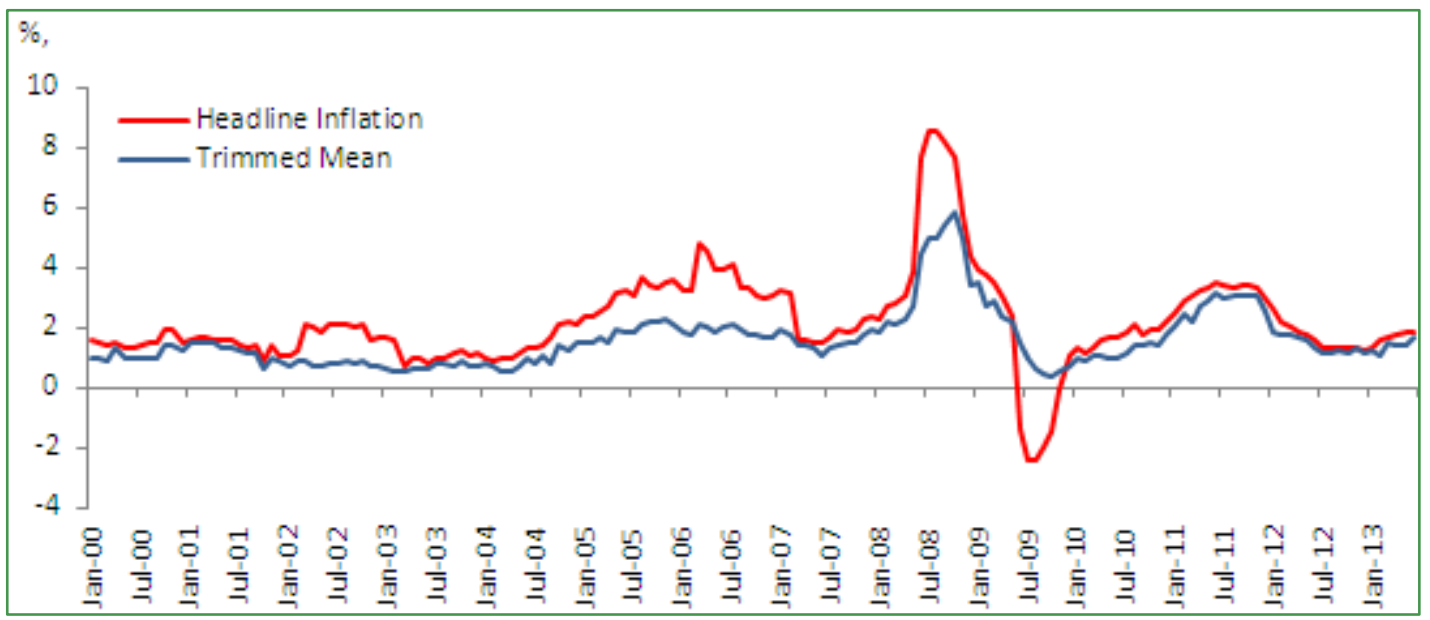

Figure 3. Headline Inflation and Trimmed Mean

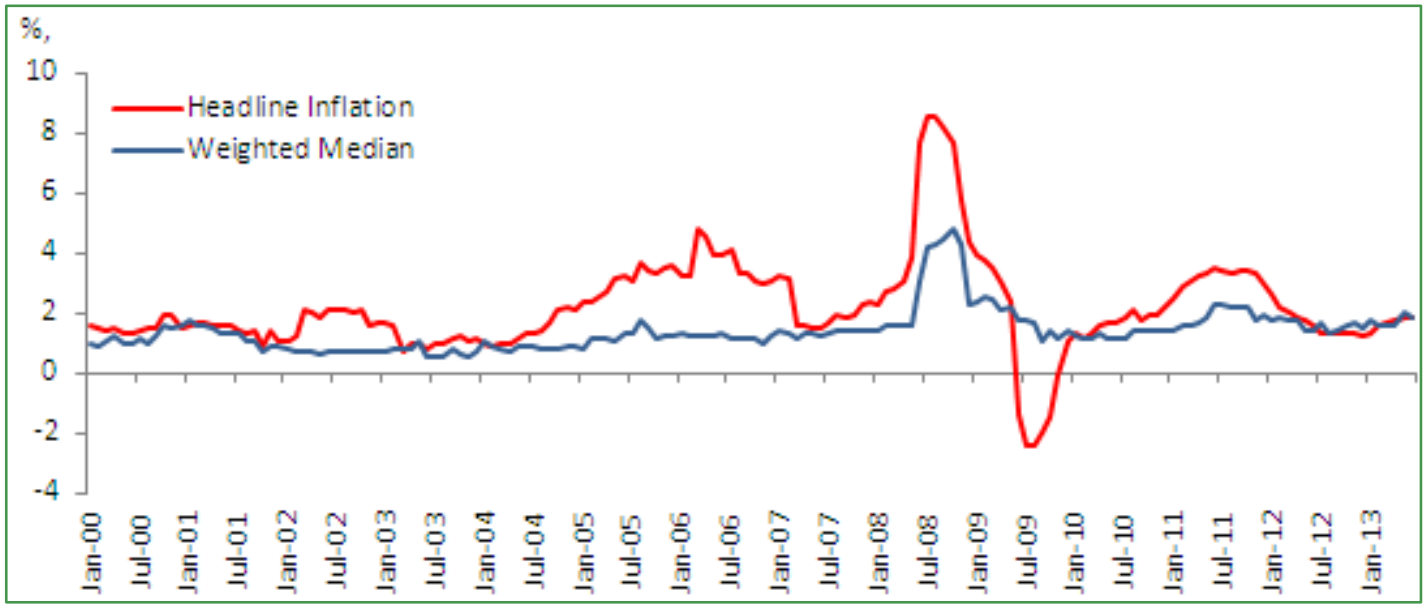

Figure 4. Headline Inflation and Weighted Median 


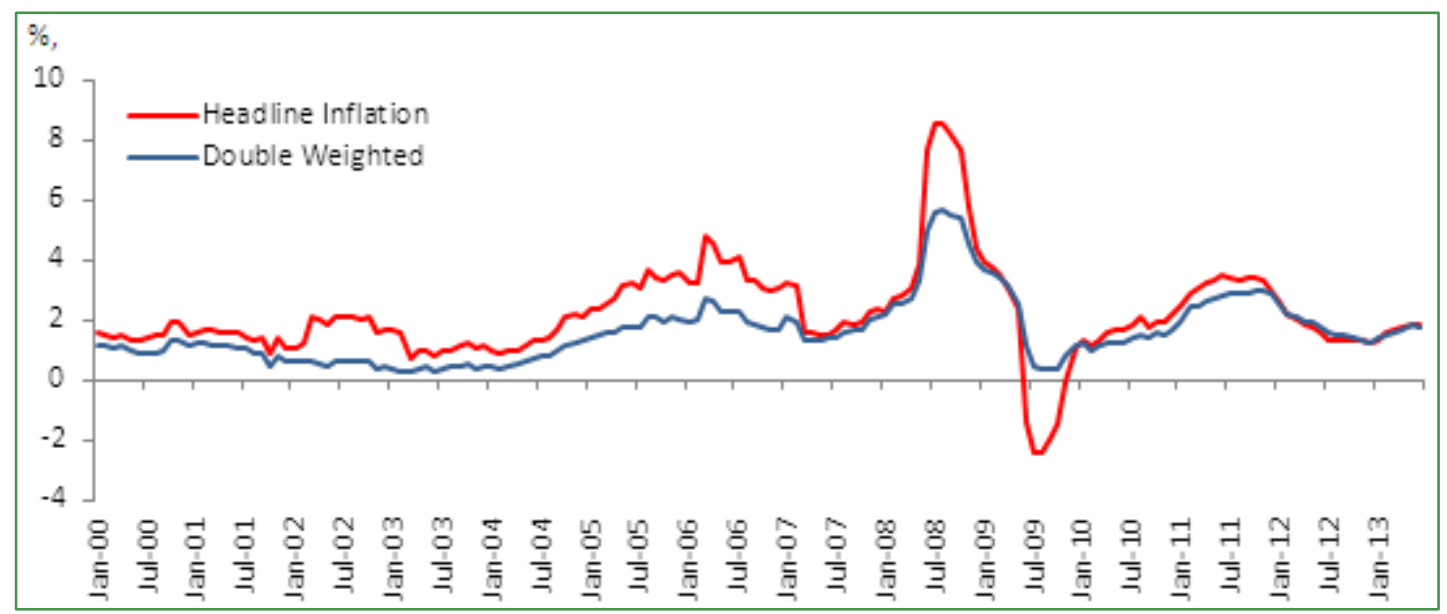

Figure 5. Headline Inflation and Double Weighted

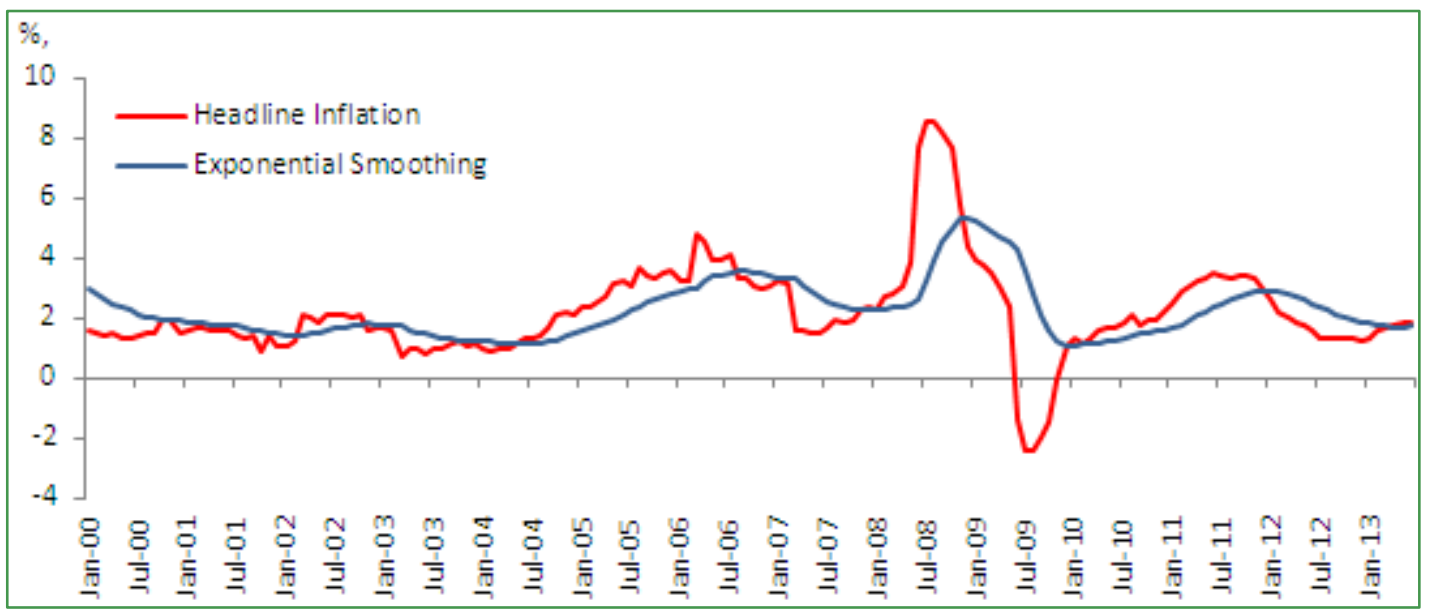

Figure 6. Headline Inflation and Exponential Smoothing

III. Plot of Headline Inflation against Model based Core Inflation Measures.

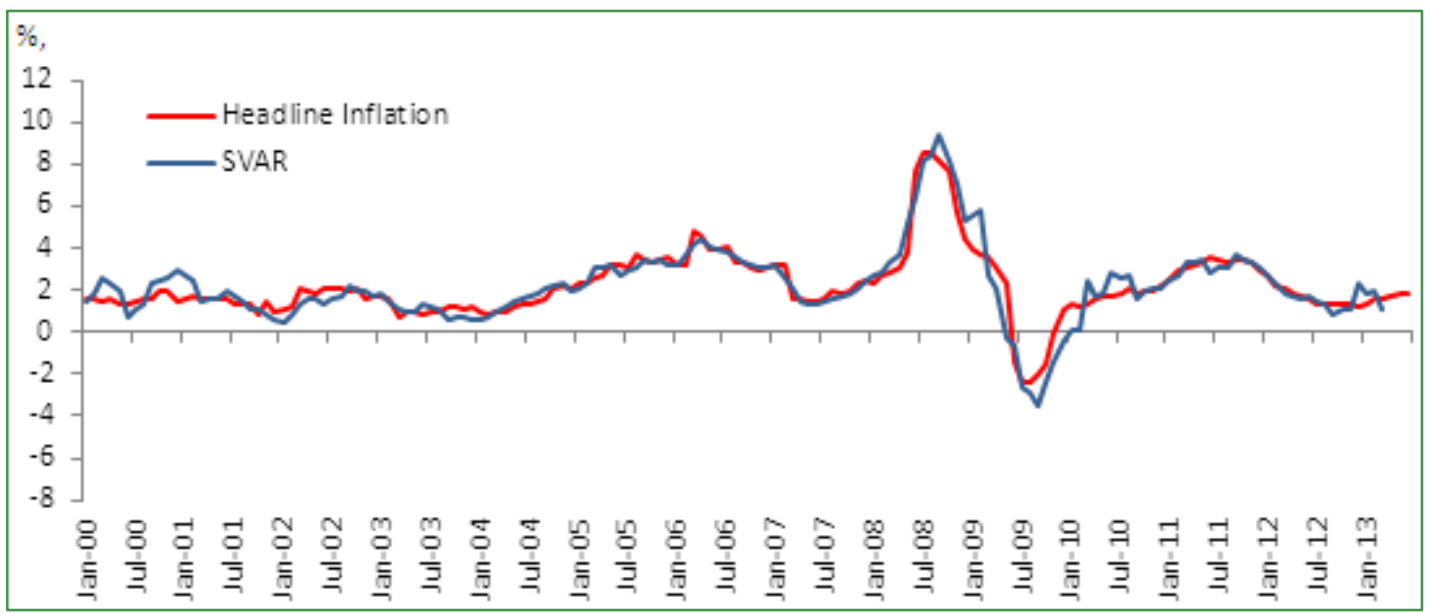

Figure 7. Headline Inflation and SVAR 


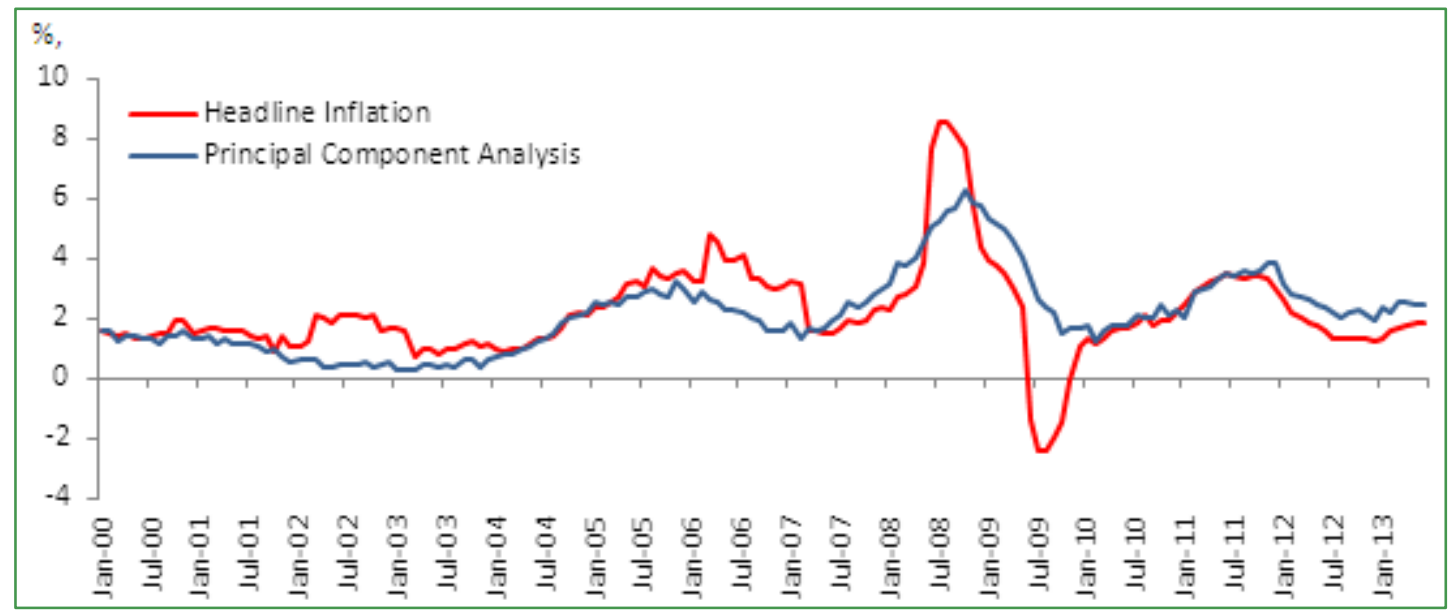

Figure 8. Headline Inflation and Principal Component Analysis

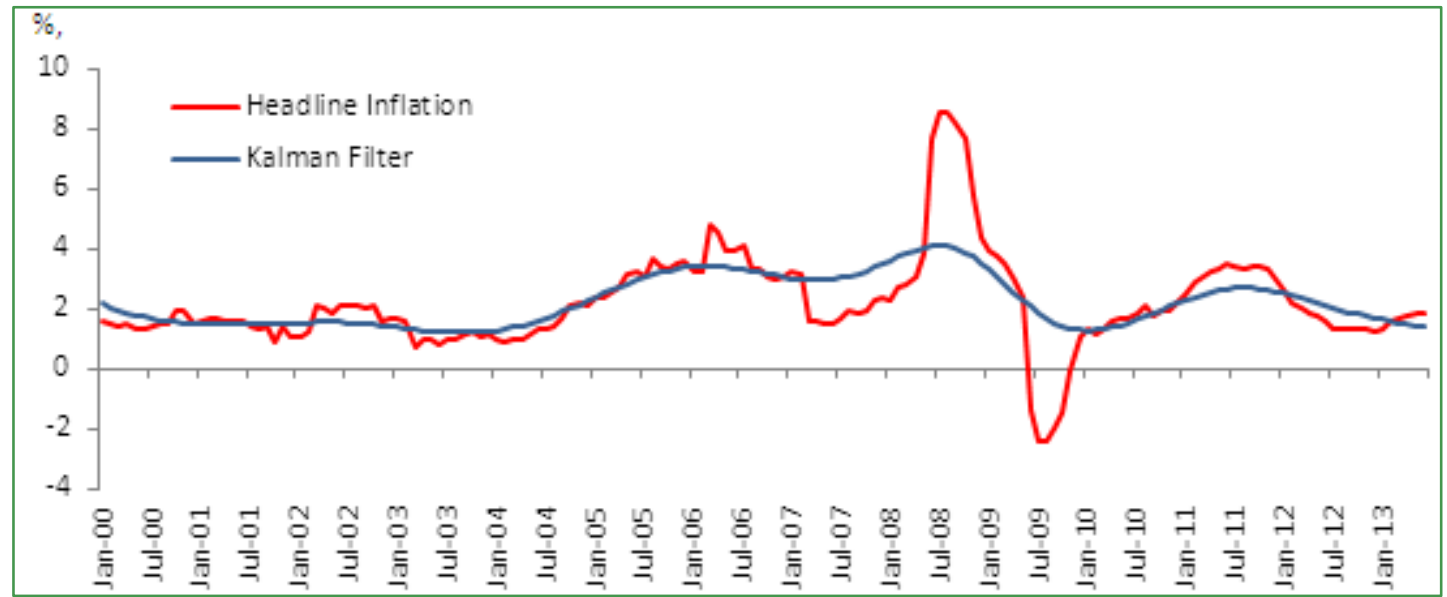

Figure 9. Headline Inflation and Kalman Filter

III. Plot of Headline Inflation against Hybrid Model based Core Inflation Measures.

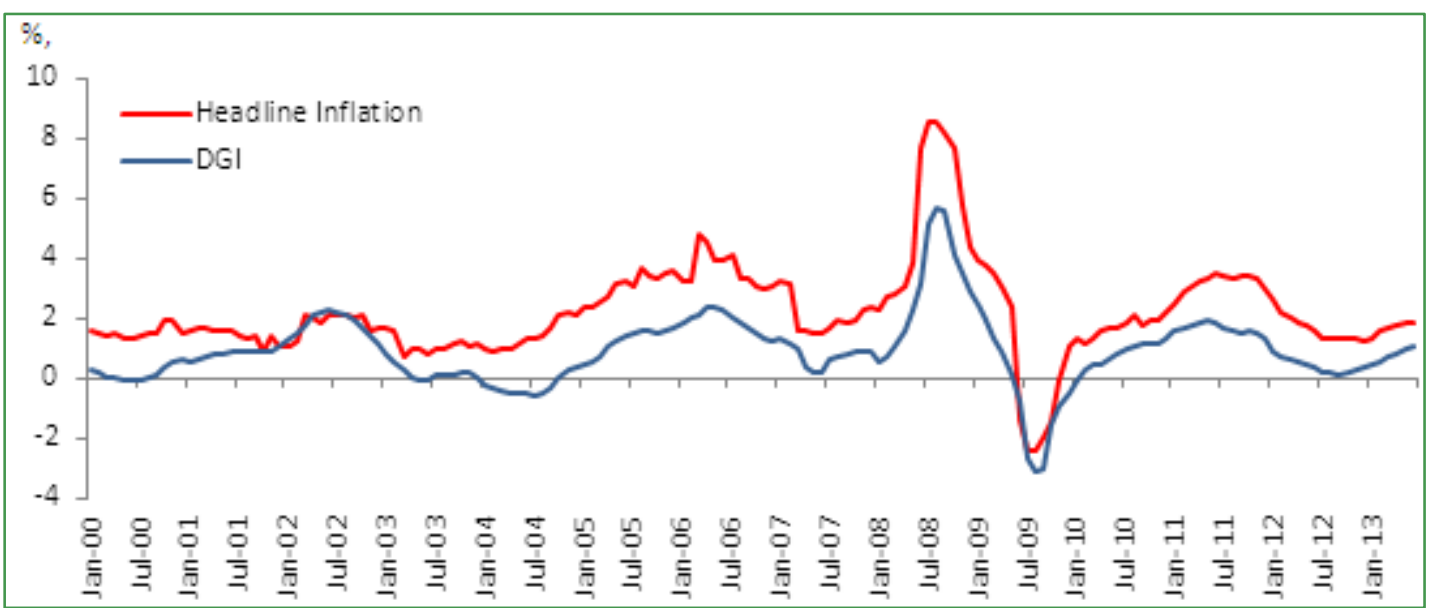

Figure 10. Headline Inflation and Domestically Generated Inflation 


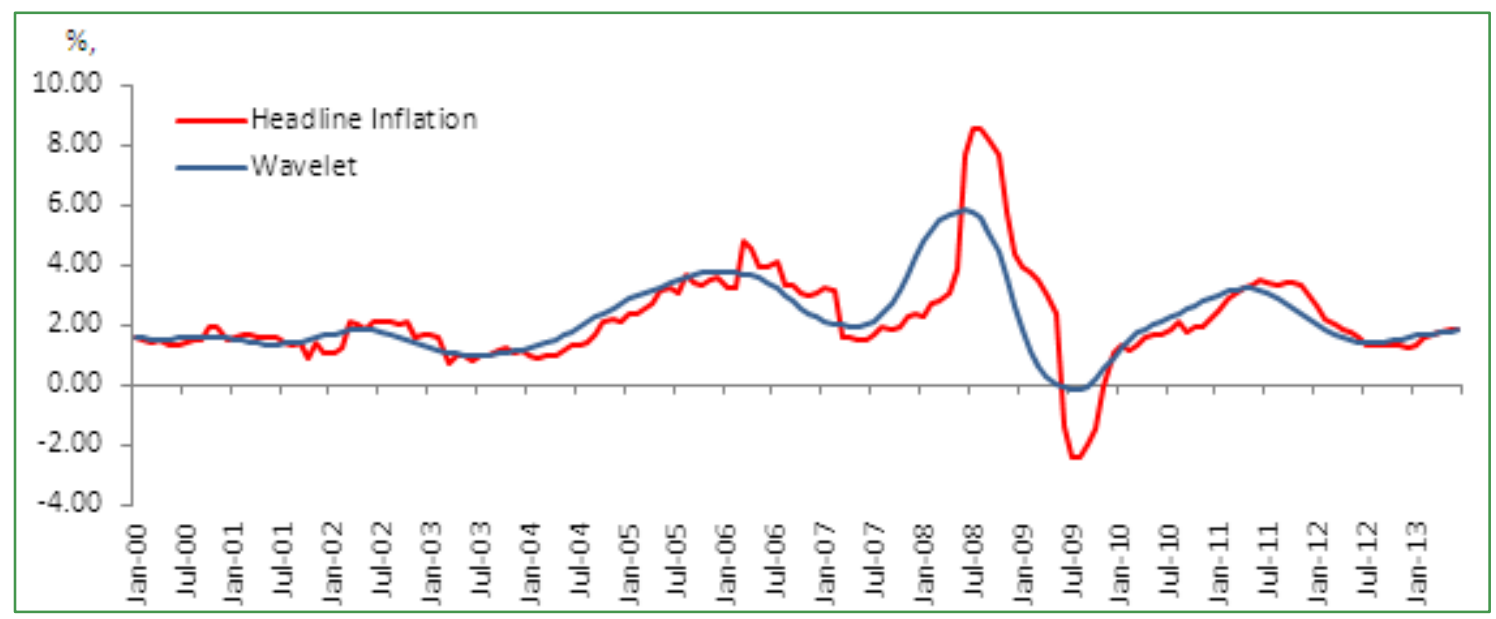

Figure 11. Headline Inflation and Wavelet Analysis

\section{REFERENCES}

[1] Wayne, M.A. (2008), "Core Inflation: A Review of Some Conceptual Issues”, FRB St. Louis Economic Review.

[2] Schreder, H.X. (1952), "Impact of Business Conditions on Investment Policies", Journal of Finance, pp. 138-73.

[3] Sprinkel, B.W. (1975), "A Year of Recession, Recovery and Decelerating Inflation”, Journal of Business, 48(1), p.p. 1-4.

[4] Tobin, J. (1981), "The Monetarist Counter-Revolution Today - An Appraisal”, Economic Journal, 91(361), p.p. 29-42.

[5] Blinder, A.S. (1997), "Measuring Short-Run Inflation for Central Bankers: Commentary", FRB St. Louis Economic Review, 79(3), .pp. 157-60.

[6] Bank Negara Malaysia , "Annual Report”, Bank Negara Malaysia, Various Issues.

[7] Roger, S. (1998), "Core Inflation: Concepts, Uses and Measurement”, RBNZ Discussion Paper, G98/9.

[8] Quah, D. \& Vahey, S.P. (1995),"Measuring Core Inflation”, Economic Journal, 105(432), p.p. 1130-44.

[9] Rich, R.W. \& Steindel, C. (2005), "A Review of Core Inflation and an Evaluation of Its Measures", FRB New York Economic Review, 13, p.p. 19-38.

[10] Mishkin, F.S. (2007), "Inflation Dynamics", NBER Working Paper, w13147.

[11] Bernanke, B.S.; Laubach, T; Mishkin, F.S. \& Posen, A.S. (1999), "Inflation Targeting: Lesson from the International Experience”, Princeton University Press.

[12] Bryan, M.F. \& Cecchetti, S.G. (1993), "The Consumer Price Index as a Measure of Inflation", FRB Cleveland Economic Review, 29(4), p.p. 15-24.

[13] Clark, T.E. (2001), “Comparing Measures of Core Inflation”, FRB Kansas City Economic Review, 86(2), p.p. 5-31.

[14] Silver, M. (2006), “Core Inflation Measures and Statistical
Issues in Choosing Among Them", IMF Working Papers, $06 / 97$.

[15] Mankikar, A. \& Paisley, J. (2004), "Core Inflation: A Critical Guide", BoE Working Paper, No.242.

[16] Armour, J. (2006), “An Evaluation of Core Inflation Measures”, BoC Working Paper, 2006-10.

[17] Marques, C.R.; Neves, P.D. \& Sarmento, L.M. (2000), "Evaluating Core Inflation Indicators", Banco de Portugal Economic Research Department, WP3-00.

[18] OECD. (2005) "Measuring and Assessing Underlying Inflation", OECD Economic Outlook, Preliminary Edition, p.p. $125-141$.

[19] Laflèche, T. \& Armour, J. (2006), "Evaluating Measures of Core Inflation”, BoC Review, p.p. 19-29.

[20] Bean, C. (2006), Commentary on "Impact of Globalisation on Monetary Policy" at FRB Kansas City, "The New Economic Geography", Jackson Hole, Wyoming.

[21] Hogan, S.; Johnson, M. \& Laflèche, T. (2001), "Core Inflation", BoC Technical Report, No.89.

[22] Monetary Authority of Singapore. (1998), "Measures of Core Inflation for Singapore", MAS Occasional Paper, No.10.

[23] Khong, F.A. (2006), "Measuring Core Inflation in Malaysia", MSc Economics Dissertation, University of Warwick.

[24] Cogley, T. (2002), “A Simple Adaptive Measure of Core Inflation", Journal of Money, Credit, and Banking, Vol.34, No.1.

[25] Coimbra, C. \& Neves, P.D. (1997), "Trend Inflation Indicators", Banco de Portugal Economic Bulletin, Vol.3, No.1.

[26] Velde, F.R. (2006), “An Alternative Measure of Inflation”, FRB Chicago Economic Perspectives, p.p. 55-65.

[27] Eckstein, O. (1981), “Core Inflation”, Prentice Hall.

[28] Laidler, D. (1990), “The Zero-Inflation Target: An Overview of the Economic Issues in Zero Inflation", C. D. Howe Institute, Policy Study 8, Toronto, p.p. 134. 
[29] Machado, J.F.; Marques, C.R., Neves, P.D. \& da Silva, A.G. (2001), "Using the First Principal Components as a Core Inflation Indicator", Banco de Portugal Economic Research Department Working Paper, No. 9-01.

[30] Maria, J.R. (2004), "On the Use of the First Principal Component as a Core Inflation Indicator", Banco de Portugal Economic Research Department Working Paper, No. 3-04.

[31] Stock, J.H. \& Watson, M.W. (1998), "Diffusion indexes", NBER Working Paper, w6702.

[32] Buiter, W.H. (1998), "The Concept and Measurement of Domestically Generated Inflation”, Preliminary, University of Cambridge.

i The authors are officers from the Monetary Policy Department and Financial Surveillance Department of Bank Negara Malaysia. They wished to thank Dr. Ahmad Razi and Farina Adam Khong for their contributions, feedbacks, comments and recommendations. The authors are responsible for all remaining errors. Author's email addresses:

The views expressed herein are solely those of the authors and do not necessarily reflect the views of Bank Negara Malaysia.
[33] Misiti, M.Y.; Oppenheim, G. \& Poggi, J.M. (2000), "Wavelet Toolbox for Use with MATLAB", The MathWorks, Inc.

[34] Schleicher, C. (2002), “An Introduction to Wavelets for Economists", Bank of Canada Working Paper, No.2002-3.

[35] Ramsey, J.B. \& Lampart, C. (1998), "The Decomposition of Economic Relationship by Time Scale Using Wavelet: Money and Income", Macroeconomic Dynamics, 2:49-71.

[36] Cotter, J. \& Dowd, K. (2006), "U.S. Core Inflation: A Wavelet Analysis", Unpublished.

[37] Heath, A.; Roberts, I. \& Bulman, T. (2004), "Inflation in Australia: Measurement and Modeling", The Future of Inflation Targeting, RBA, p.p. 167-207. 